\title{
Phytomicrobiomes for agro-environmental sustainability
}

M icrobes associated with plant and soil plays several significant roles for the environment and without them the existence of life is quite impossible. They have been known to exist in every habitat type of the earth even harsh and interact with other organism and plant-microbes. Phytomicrobiomes are microbes allied with plant i.e. epiphytic (above ground plant surface), endophytic (internal tissues) and rhizospheric (root associated soil) region tends to benefits its host (Figure 1). The microbial community associated with plants interacts with them helps in boosting the growth and development of plant by controlling the pathogens. Plant growth promoting microbiomes could be used as bioinoculants in term of biopesticides and biofertilizers for agro-environmental sustainability. In agriculture sector they have been known to utilize as bioinoculants, an alternative source of agro-chemicals. On the other hand, in environment, phytomicrobiomes could be helpful in the bioremediation the environmental contaminant caused by the anthropogenic activities of humans.

The phytomicrobiomes play a noteworthy role in plant growth promotion, plant protection and nutrient cycling in agroenvironmental systems. The term epiphytic or phyllosphere is used not only for the leaves of the plants but also used for all aerial plant parts including stalks, fruits, flower, bark, and pollens. The phyllosphere harbors diverse and complex microbial community including bacteria, fungi, yeast, protists, algae, bacteriophages and among which bacteria is the most dominant colonizer [1]. The culturable phyllospheric microbial communities with cereal crops belong to diverse genera such as Bacillus, Exiguobacterium, Janthinobacterium, Methylobacterium, Pseudomonas and Staphylococcus [2]. The microbial diversity present on the above ground parts of plant may be parasitic, commensal or mutualistic. The colonist of phyllosphere has both deleterious and beneficial impact on the plants. Plant surface microbiota plays a crucial role for its host by protecting them from the stresses such as harmful ultraviolet radiations and oxidative stresses and in return plant provides the leaf surface, nutrients and minerals.

\author{
Ajar Nath Yadav (i) \\ Microbial Biotechnology Laboratory, \\ Department of Biotechnology, \\ Dr. Khem Singh Gill Akal College of Agriculture, \\ Eternal University, Baru Sahib, \\ Sirmour, Himachal Pradesh, India. \\ Email: ajarbiotech@gmail.com
}

Saprophytic microbes play a vital role in the essential elements cycling, remediation of residual pesticides, and hydrocarbons pollutants which helps in maintaining the health of the plants [3]. There are huge and vast varieties of finding as phytomicrobiomes for agro-environmental sustainability (Figure 2). Phyllospheric microbiomes have been recognized for their potential applications in the sector of both agriculture and environment. In agriculture, they are known to be used as biofertilizer, biopesticides and phytostimulators which help the growth promotion of the plant by direct (supplying nutrients and plant growth regulators) and indirect (invading plant pathogens and alleviating abiotic stress mainly harmful radiations) mechanism of actions. Diverse species of the epiphytic microbes associated with different plant parts surface have been reported as plant growth promoting epiphytic microbes and play significant role in crop improvement. In environment, the phyllosphere microbiomes have been recognized for the bioremediation of the pollutants. In a report, fungi Penicillium oxalicum associated with the leaves of Amaranthus cruentus was reported for aromatic hydrocarbons as the strain was reported for exhibiting laccases, and lignin peroxidases enzyme activity [4]. In another report, two bacterial strain, Alcaligenes sp. and A. feacalis isolated from the Ervatamia divaricata, Hibiscus rosa-sinensis, Ixora chinensis, and Amaranthus cruentus was reported for degradation of naphthalene and phenanthrene [4].

Endophytes are microbes that are present asymptomatically in plants. Endophytic microbes residing internal 


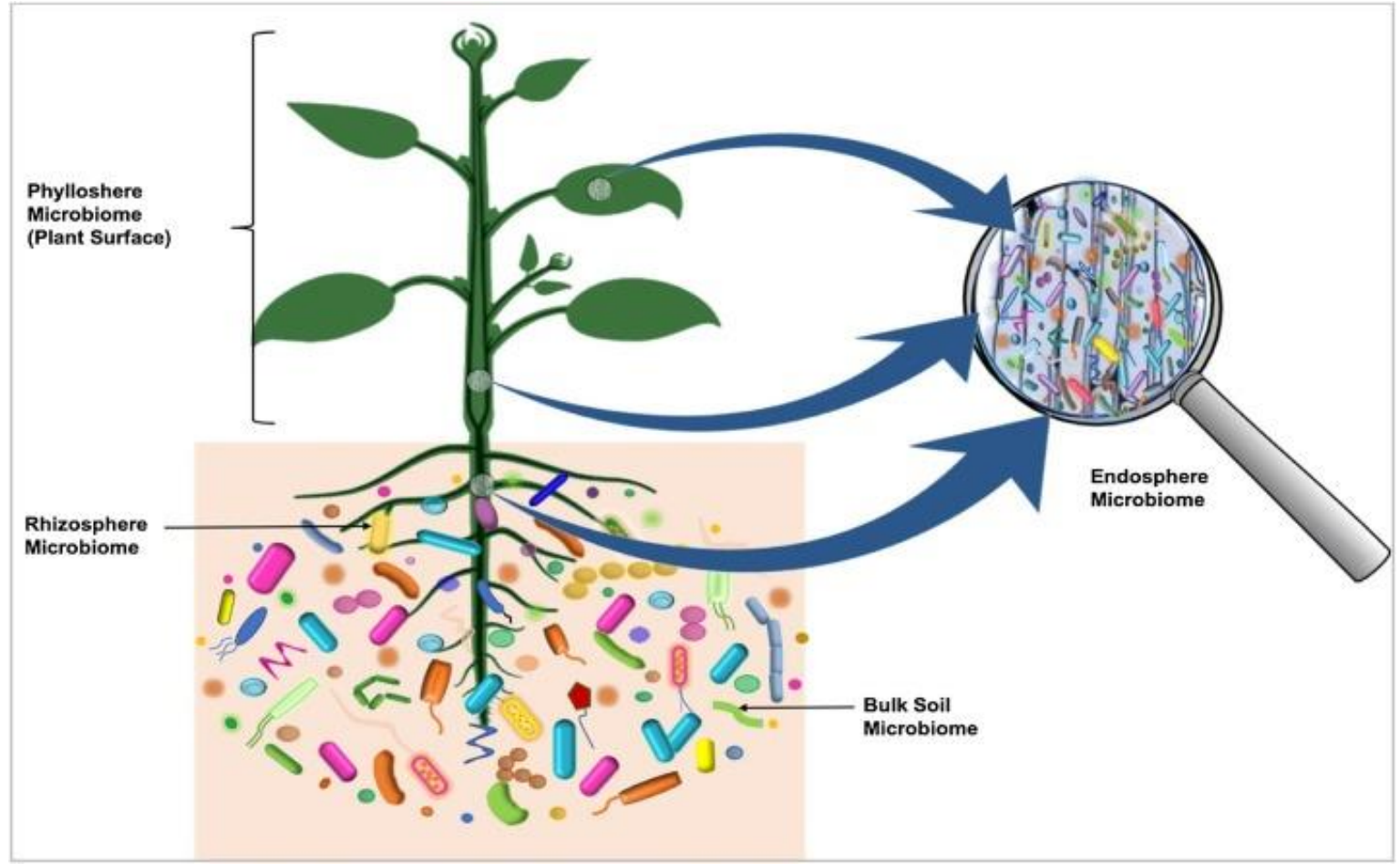

Figure 1: Phytomicrobiomes (Source-Dastogeer et al. [24]).

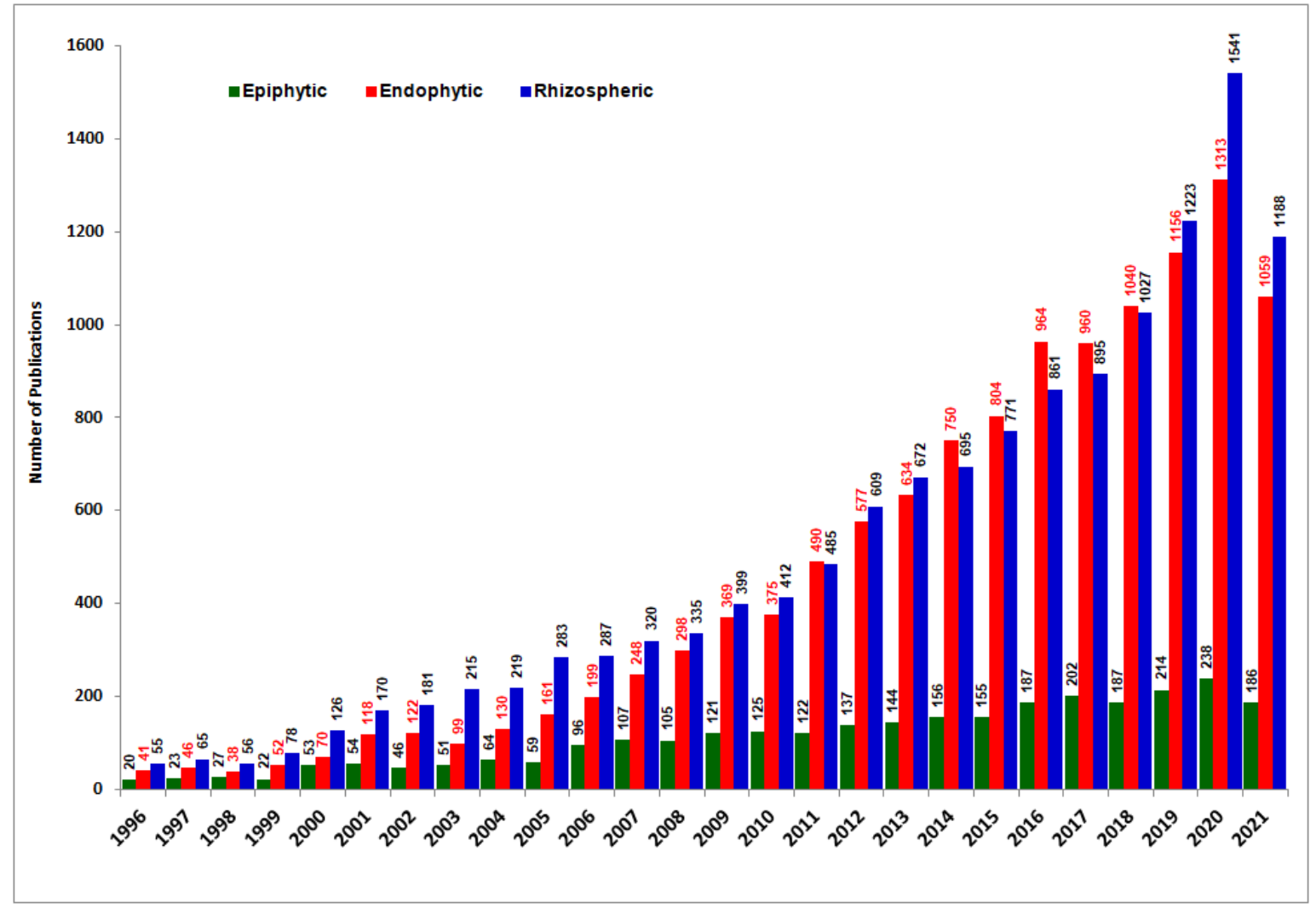

Figure 2: Number of research publications on phytomicrobiomes [Source-PubMed]. 
plant tissues could be either transmitted horizontally, via seed from generation to generation or obtained from the atmosphere which is known as vertical transmission [5]. Endophytic microbes usually arise from the rhizosphere or phyllosphere and plant through natural opening or wounds with uses various enzymes including cellulases, pectinases and proteinase [6]. Endophytic microbe benefits by improving its growth under both normal and challenging conditions. Endophytic microbes are often functional in transporting nutrients from the soil to plants, regulate plant growth, increase plant stress tolerance, suppress virulence in pathogens, and enhance plant disease resistance can increase, reduce oxidative stress of hosts, deter feeding by herbivores and suppress the growth of competing plant species [7]. The endophytic microbes belong to various groups of microbes including fungi archaea and, bacteria among which bacteria is predominant followed by fungi and archaea.

Endophytic microbes are agriculturally imperative because they have capability to enhance growth and development of plant by utilizing various PGP characteristics and mechanisms. Microbial endophytes stimulate the plant growth via initiating solubilization of macro and micronutrients including phosphorus, potassium and zinc, fixation of nitrogen, production of plant growth regulators such as gibberellins, auxin, and ethylene and triggering host plant defense responses against phytopathogens by various mechanisms including production of siderophores, hydrogen cyanide, ACC deaminase, the supply of vigorous vitamins to plants, and via competition, antibiosis, parasitism. These microbes could be used as an alternative source to traditional agricultural techniques $[8,9]$.

Rhizosphere is the biologically active zone of the soil which is associated with the roots of the plant. This zone contains several type of soil borne microbes which could be bacteria and fungi. Among the all group of microbes bacteria also dominate the rhizospheric region like epiphytic and endophytic region. The microbes inhibiting in the active zone of soil is attracted by the wide variety of chemical compounds released by the roots of the plant. The interaction between the plant and microbes could be beneficial to the both plant and the microbes or neither of the two. The interaction study between the soil microbes in plant i.e. rhizospheric region is important for the understanding of the intrinsic processes such as cycling of nutrients, functioning of ecosystem and sequestration of carbon [10]. The study of interaction between these two is also important for the development of sustainable management practices and products including biofertilizer and biopesticides [11].

The dominant microbial group, bacteria are mostly known and recommended for the development of the biofertilizer as it has been known that $2.5 \%$ of the population of bacteria promotes the plant growth and they have referred as plant growth promoting rhizobacteria. These plant associated microorganisms as well as soil microbiomes, via different mechanisms, enhance plant growth and soil health. Disease suppression, nutrient availability, increased immunity to abiotic stress and biotic stresses are each of which leads to enhance the plant productivity.
Rhizospheric microbial communities can be used as bioinoculants as biopesticides and biofertilizers, they promote plant growth through $\mathrm{P}$ and $\mathrm{K}$ solubilization, nitrogen fixation, exopolysaccharide secretion, antagonistic activity, organic matter decomposition, and Fe-chelating compounds production [12;13]. Phosphorus is one of essential nutrient required in large quantity for production of ATP, phospholipids, and increases the photosynthesis in plant [14]. It is well know that a huge proportion of $\mathrm{P}$ in the soil is not in a soluble forms, that's why plant are unable to uptake the $\mathrm{P}$ present in soil [15]. P-solubilizers posess the capability of solubilizing insoluble forms of $\mathrm{P}$ and make it available to the plants for its use. P-solubilizing microbes reported from rhizosphere of diverse crops include Acinetobacter, Aspergillus, Bacillus, Burkholderia, Enterobacter, Erwinia, Halococcus, Flavobacterium, Penicillium, Rhodococcus, and Serratia [16]. Production of plant growth hormons is widespread among rhizospheric bacteria. The most commonly occurring phytohormone is auxin (indole acetic acid) produced by huge number of microbes. Gibberellins are another plant growth promoting hormones produced by number of microbes including bacteria and fungi. Indole acetic acid, and gibberellins are involved in a number of developmental and physiological processes including seed germination, seedling emergence, stem and leaf growth, floral induction and flower or/and fruit growth, regulation of vegetative and delay of senescence and reproductive (bud) dormancy $[17,18]$. Cytokinin, is also important phyto-hormones produced by microbes. This plant growth regulator mediates the responses to various extrinsic factors, such as nutrients and water availability in plants [19]. Siderophores, the compound of low molecular weight which chelated the soil iron is produced by several rhizospheric bacteria and fungi and their number is increasing as new siderophores are being identified [20, 21]. 1aminocyclopropane-1-carboxylate (ACC) deaminase production is an important mechanism which plays a vital role in providing tolerance under abiotic stress conditions. ACC deaminase present in PGP microbes regulates the ethylene production under the stress condition by metabolizing ACC to $\alpha$-ketobutyrate and ammonia $[22,23]$. PGP rhizobacteria could also be utilized to mitigate the biotic stresses for sustainable agriculture. The rhizospheric microbes also an important plant associated microbes which helps in sustaining the environmental health. The environmental sustainability needs to create the balance between the future's need and resources. In this scenario, PGP microbes for restoration of agro-environment to their original shape are gaining much attention of both environmentalists as well as agronomists. PGP microbiomes could be used as bioinoculants (biopesticides and biofertilizers) for agricultural sustainability. These beneficial microbiomes could be helpful in the bioremediation the environmental contaminant caused by the anthropogenic activities of humans.

\section{CONFLICTS OF INTEREST}

There are no conflicts of interest. 


\section{REFERENCES}

1. Yadav AN. Beneficial plant-microbe interactions for agricultural sustainability. J Appl Biol Biotechnol. 2021; 9(1):1-4. https://doi.org/10.7324/JABB.2021.91ed

2. Yadav AN, Kumar V, Dhaliwal HS, Prasad R, Saxena AK. Microbiome in Crops: Diversity, Distribution, and Potential Role in Crop Improvement. Crop improvement through microbial biotechnology. Amsterdam: Elsevier; 2018. p. 305-32. https://doi.org/10.1016/B978-0-444-63987-5.00015-3

3. Müller T, Ruppel S. Progress in cultivation-independent phyllosphere microbiology. FEMS Microbiol Ecol. 2014; 87(1):217. https://doi.org/10.1111/1574-6941.12198

4. Kannangara S, Undugoda L, Rajapaksha N, Abeywickrama K. Depolymerizing activities of aromatic hydrocarbon degrading phyllosphere fungi in Sri Lanka. J Bioremediat Biodegrad. 2016; 7(06):1-9. https://doi.org/10.4172/2155-6199.1000372

5. Rana KL, Kour D, Kaur T, Devi R, Yadav AN, Yadav N, Dhaliwal HS, Saxena AK. Endophytic microbes: biodiversity, plant growth-promoting mechanisms and potential applications for agricultural sustainability. Antonie van Leeuwenhoek. 2020; 113(8):1075-107. https://doi.org/10.1007/s10482-020-01429-y

6. Rana KL, Kour D, Yadav N, Yadav AN. Endophytic microbes in nanotechnology: Current development, and potential biotechnology applications. In: Kumar A, Singh VK, editors. Microbial Endophytes: Woodhead Publishing; 2020. p. 231-62. https://doi.org/10.1016/B978-0-12-818734-0.00010-3

7. Rana KL, Kour D, Yadav N, Yadav AN. Endophytic microbes in nanotechnology: Current development, and potential biotechnology applications. In: Microbial Endophytes: Prospects for Sustainable Agriculture. Edited by Kumar A, Singh VK. Woodhead Publishing; 2019: 231-262. https://doi.org/10.1016/ B978-0-12-818734-0.00010-3

8. Kour D, Kaur T, Devi R, Yadav A, Singh M, Joshi D, Singh J, Suyal DC, Kumar A, Rajput VD, et al. Beneficial microbiomes for bioremediation of diverse contaminated environments for environmental sustainability: present status and future challenges. Environ Sci Poll Res. 2021; 28(20):24917-39. https://doi.org/ 10.1007/s11356-021-13252-7

9. Kumar A, Yadav AN, Mondal R, Kour D, Subrahmanyam G, Shabnam AA, Khan SA, Yadav KK, Sharma GK, Cabral-Pinto M, et al. Myco-remediation: A mechanistic understanding of contaminants alleviation from natural environment and future prospect. Chemosphere. 2021; 284:131325. https://doi.org/ 10.1016/j.chemosphere.2021.131325

10. Yadav AN. Biodiversity and bioprospecting of extremophilic microbiomes for agro-environmental sustainability. J Appl Biol Biotechnol. 2021; 9(3):1-6. $\quad$ https://doi.org/10.7324/ JABB.2021.9301

11. Kour D, Rana KL, Yadav N, Yadav AN, Kumar A, et al. Rhizospheric Microbiomes: Biodiversity, Mechanisms of Plant Growth Promotion, and Biotechnological Applications for Sustainable Agriculture. In: Kumar A, Meena VS, editors. Plant Growth Promoting Rhizobacteria for Agricultural Sustainability : From Theory to Practices. Singapore: Springer Singapore; 2019. p. 19-65. https://doi.org/10.1007/978-981-13-7553-8_2

12. Naik K, Mishra S, Srichandan H, Singh PK, Sarangi PK. Plant growth promoting microbes: Potential link to sustainable agriculture and environment. Biocat Agric Biotechnol. 2019; 21:101326. https://doi.org/10.1016/j.bcab.2019.101326

13. Yadav AN, Verma P, Kumar S, Kumar V, Kumar M, Kumari Sugitha TC, Singh BP, Saxena AK, Dhaliwal HS. Actinobacteria from rhizosphere: Molecular diversity, distributions, and potential biotechnological applications. In: Singh BP, Gupta VK, Passari AK, editors. New and Future Developments in Microbial
Biotechnology and Bioengineering. Amsterdam: Elsevier; 2018. p. 13-41. https://doi.org/10.1016/B978-0-444-63994-3.00002-3

14. Kour D, Rana KL, Kaur T, Yadav N, Yadav AN, Kumar M, Kumar V, Dhaliwal HS, Saxena AK. Biodiversity, current developments and potential biotechnological applications of phosphorus-solubilizing and -mobilizing microbes: A review. Pedosphere. 2021; 31(1):43-75. https://doi.org/10.1016/S10020160(20)60057-1

15. Lopes MJdS, Dias-Filho MB, Gurgel ESC. Successful plant growth-promoting microbes: Inoculation methods and abiotic factors. Front Sustain Food Sys. 2021; 5:48. https://doi.org/10.3389/fsufs.2021.606454

16. Kour D, Rana KL, Kaur T, Sheikh I, Yadav AN, Kumar V, Dhaliwal HS, Saxena AK. Microbe-mediated alleviation of drought stress and acquisition of phosphorus in great millet (Sorghum bicolour L.) by drought-adaptive and phosphorussolubilizing microbes. Biocatal Agric Biotechnol. 2020; 23:101501. https://doi.org/10.1016/j.bcab.2020.101501

17. Crozier A. Biosynthesis of hormones and elicitor molecules. Biochemistry and molecular biology of plants. 2000.

18. King RW, Evans LT. Gibberellins and flowering of grasses and cereals: prizing open the lid of the "florigen" black box. Ann Rev Plant Biolo. 2003; 54(1):307-28. https://doi.org/10.1146/annurev. arplant.54.031902.135029

19. Maheshwari DK, Dheeman S, Agarwal M. Phytohormoneproducing PGPR for sustainable agriculture. Bacterial metabolites in sustainable agroecosystem: Springer; 2015. p. 159-82.

20. Kour D, Rana KL, Yadav AN, Yadav N, Kumar M, Kumar V, Vyas P, Dhaliwal HS, Saxena AK. Microbial biofertilizers: Bioresources and eco-friendly technologies for agricultural and environmental sustainability. Biocatal Agric Biotechnol. 2020; 23:101487. https://doi.org/10.1016/j.bcab.2019.101487

21. Kour D, Rana KL, Yadav AN, Sheikh I, Kumar V, Dhaliwal HS, Saxena AK. Amelioration of drought stress in Foxtail millet (Setaria italica L.) by P-solubilizing drought-tolerant microbes with multifarious plant growth promoting attributes. Environ Sustain. 2020; 3(1):23-34. https://doi.org/10.1007/s42398-02000094-1

22. Kumar V, Joshi S, Pant NC, Sangwan P, Yadav AN, Saxena A, Singh D. Molecular approaches for combating multiple abiotic stresses in crops of arid and semi-arid region. In: Singh SP, Upadhyay SK, Pandey A, Kumar S, editors. Molecular Approaches in Plant Biology and Environmental Challenges. Singapore: Springer; 2019. p. 149-70, https://doi.org/10.1007/978981-15-0690-1_8

23. Kashyap BK, Solanki MK, Pandey AK, Prabha S, Kumar P, Kumari B. Bacillus as plant growth promoting rhizobacteria (PGPR): a promising green agriculture technology. Plant health under biotic stress: Springer; 2019. p. 219-36. https://doi.org/10.1007/978-981-13-6040-4_11

24. Dastogeer KMG, Tumpa FH, Sultana A, Akter MA, Chakraborty A. Plant microbiome-an account of the factors that shape community composition and diversity. Curr Plant Biol. 2020; 23:100161. https://doi.org/10.1016/j.cpb.2020.100161

\section{How to cite this article:}

Yadav AN. Phytomicrobiomes for agro-environmental sustainability. J App Biol Biotech. 2021;9(5): i-iv. DOI: $10.7324 / \mathrm{JABB} .2021 .95 \mathrm{ed}$ 